\title{
Micro Frictions, Asset Pricing, and Aggregate Implications*
}

\author{
Jack Favilukis ${ }^{\dagger}$ and Xiaoji Lin ${ }^{\ddagger}$
}

January 24, 2011

\begin{abstract}
We use asset pricing insights to study importance of micro-level frictions for aggregate quantities. In our model, the relevant stochastic variable is a stationary growth rate (necessary to produce high Sharpe Ratios in a Long Run Risk world), as opposed to a trend-stationary level of productivity. This naturally implies a heteroscedastic and timedependent aggregate investment rate; contributing to the recent debate between Khan and Thomas (2008) and Bachmann, Caballero, and Engel (2010), we find that non-convex costs are not necessary to match these moments. Our best model, combining convex and nonconvex costs, matches aggregate macro-economic and micro-level investment moments, as well as the high Sharpe Ratio of equity. JEL classification: E23, E44, G12
\end{abstract}

*We would like to thank Frederico Belo, Bob Goldstein, Francois Gourio, Ravi Jagannathan, Stavros Panageas, Dimitris Papanikolaou (NBER discussant), Monika Piazzesi, Neng Wang, Amir Yaron, and Lu Zhang for helpful comments. We thank the seminar participants at the London School of Economics, University of Minnesota and NBER 2010 Asset Pricing Summer Institute. All remaining errors are our own.

${ }^{\dagger}$ Department of Finance, London School of Economics and Political Science and FMG, Houghton Street, London WC2A 2AE, U.K. Tel: (044)-020-7955 6948 and E-mail:j.favilukis@lse.ac.uk

${ }^{\ddagger}$ Department of Finance, London School of Economics and Political Science and FMG, Houghton Street, London WC2A 2AE, U.K. Tel: (044)-020-7852-3717 and E-mail:x.lin6@lse.ac.uk 


\section{Introduction}

There exists a long standing debate in the macro economic literature over whether modeling micro level frictions is important for matching aggregate quantities. Khan and Thomas (2008) argue that in general equilibrium prices adjust making micro frictions irrelevant. However Bachmann, Caballero, and Engel (2010) show that non-convex frictions can matter for aggregate quantities under certain conditions. In particular they argue that aggregate investment rate is heteroscedastic and time-dependent; non-convex frictions help match the heteroscedasticity of aggregate investment, which standard frictionless models cannot do.

Our key finding is that shocks to the growth rate as opposed to the level of productivity (exactly the types of shocks necessary to produce high Sharpe Ratios in a Long Run Risk world Bansal and Yaron (2004)) naturally imply aggregate investment rates which are heteroscedastic and time dependent. While non-convex frictions can matter for aggregate quantities under some calibrations (consistent with Bachmann et. al.), these types of frictions are not necessary to match the aggregate investment moments emphasized by Bachmann et. al.

Our preferred model combines convex costs (which help with aggregate investment dynamics) and non-convex costs (which help with firm level investment dynamics but are not necessary for the aggregate) and is able to sufficiently match aggregate real business cycle moments; additional aggregate investment dynamics emphasized by Bachmann et. al.; high Sharpe Ratios and interest rates which are low and smooth; as well as firm level investment rates and distributions. Since most of the work in our preferred model is done by convex costs, yet the model sufficiently matches both micro and macro observations, the results provide a justification for models such as Jermann (1998), Croce (2010), Kaltenbrunner and Lochstoer (2010) who use a representative firm with convex costs only.

The heart of the debate between Khan and Thomas (2008) and Bachmann, Caballero, and Engel (2010) lies in whether general equilibrium forces can cancel out aggregate investment demand implied by micro lumpy investment. Consider firms that face a non-convex (ie fixed) cost to invest; such firms will have a cut off rule in deciding whether to invest a large amount or 
none at all. Suppose many firms are just below the cutoff and not investing, then a small positive aggregate shock can drive a large number of firms over the hump, resulting in large swings of investment as all firms suddenly invests (extensive margin). Without fixed costs firms will only adjust the quantity of investment (intensive margin) and such large swings in response to small shocks would not occur. By the logic of Khan and Thomas, general equilibrium forces prevent a large number of firms from concentrating just below the cutoff because investment is valuable and prices would reflect this, imploring some of the firms to invest earlier. However, Bachmann, Caballero, and Engel (2010) show that both adjustment costs and general equilibrium forces play a relevant role. In particular, when extensive margin is calibrated to have a more important role in shaping aggregate investment than general equilibrium constraints, non-convex frictions can have a consequential effect on aggregate quantities.

While the models above are solely calibrated to match multiple aggregate and firm level quantities, they fail to match the asset prices observed in the data; this is a problem endemic to most standard models, as observed by Mehra and Prescott (1985). Moreover different calibrations of capital adjustment costs in Khan and Thomas (2008) versus Bachmann, Caballero, and Engel (2010) result in lack of restrictions in identifying the form and size of micro-rigidities making it harder to interpret the results. Asset pricing moments can provide an additional mechanism to identify the appropriate way to model frictions and shed light on the above debate. To that end, we use insights from the finance literature to build a model with a non-trivial cross-section of heterogenous firms and realistic asset prices. In particular household preferences are recursive and the growth rate (as opposed to the level) of shocks is stationary. Tallarini (2000), Bansal and Yaron (2004), Croce (2010), Kaltenbrunner and Lochstoer (2010) show that such shocks are important for asset prices. We then study the implications of frictions for aggregate quantities and for asset pricing in such a model.

The model mechanism is as follows. When, as in standard models, shocks are to the level of productivity, firms have an optimal level of capital associated with each productivity level. When the productivity level increases due to a positive shock, so does optimal capital and firms 
choose investment rate based on the distance to the optimum. Subsequent positive shocks are counterbalanced by mean reversion, resulting in little change to the currently optimal (high) productivity and capital levels. The result is an initial jump in aggregate investment rate, followed by a slow decline towards zero as more positive shocks come because firms are closer and closer to their optimal capital; this can be seen in the upper panel of Figure 3. On the other hand when the growth of productivity is trend stationary, a shock to productivity implies a permanent change in the level of productivity. Subsequent positive shocks are again counterbalanced by mean reversion, but this time it is the growth rate, rather than level of productivity that stays high. This results in further increases to productivity and optimal capital, requiring even more investment. This leads to time dependence in investment rate, with investment rate growing (falling) as the expansion (recession) gets longer.

These trend stationary shocks to the growth rate (as opposed to the level) of productivity imply changes to productivity not only today or tomorrow, but for many years to come. Through production, these shocks also affect consumption over may periods forward. While an agent with CRRA preferences only cares about changes to today's consumption growth rate, agents with recursive preferences also care about these long term changes, making this economy riskier from their perspective. Therefore, these shocks, combined with recursive preferences, produce high Sharpe Ratios as in Bansal and Yaron (2004).

The rest of the paper is laid out as follows. In section 2 we review the relevant literature and empirical facts. In section 3 we write down our model. In section 4 we present and discuss the model's results. Section 5 concludes.

\section{Review of Literature and Empirical Facts}

\section{$2.1 \quad$ Investment}

We will first briefly review empirical properties of firm level and aggregate investment, as well as some of the models used to match these facts. 
Firm level investment tends to be lumpy, with periods of inaction followed by periods of large investment (spikes); similar plant level findings have been documented by Doms and Dunne (1998), Davis and Haltiwanger (1992), Caballero, Engel, and Haltiwanger (1995), Cooper and Haltiwager (2006). These papers have found that non-convex (fixed) costs of investment are necessary at the plant level to match these spikes and inactions. For example at the plant level, investment rate has an autocorrelation of 0.05. Cooper and Haltiwager (2006) show that such a low autocorrelation can happen if firms face fixed costs and invest nothing most of the time while spike up investment periodically. Convex costs instead lead to positively autocorrelated investment because firms with high investment demand invest step by step as huge investment spikes in a single period are extremely costly. We find that at the firm level autocorrelation is 0.36, making fixed costs less important.

Despite this rich structure for micro investment, it is not clear that it is relevant for thinking about aggregate ivestment. For example Cooper and Haltiwager (2006) solve a partial equilibrium model with a rich specification of adjustment costs. In their model, non-convex costs are crucial for matching firm level investment, however when they compute their model's implied aggregate investment, they find that a model with convex costs alone does reasonably well. Convex costs models do not track aggregate data well only around turning points in aggregate productivity. Thomas (2002) argues that even during such turning points, non-convex costs are irrelevant once general equilibrium forces are taken into account; essentially prices adjust in a way to prevent large swings in investment. Their general equilibrium model with firm level nonconvex costs has aggregate results identical to a frictionless model. This is a sharp contradiction to partial equilibrium analysis of Caballero, Engel, and Haltiwanger (1995), Caballero, Engel, and Haltiwanger (1997), and Caballero and Engel (1999). Khan and Thomas (2003), Khan and Thomas (2008) confirm that the above irrelevance results holds in a more general model. Veracierto (2002) shows that investment irreversibility does not play a significant role in a standard real business cycle model.

Aggregate investment rate $(\mathrm{I} / \mathrm{K})$ is less volatile than output. Bachmann, Caballero, and Engel 
(2010) highlight two additional features of aggregate investment: it is heteroscedastic and time dependent. Volatility in investment rate is high when past I/K is high. In Figure 2 (reproduced from Bachmann, Caballero, and Engel (2010)) I/K is regressed against lagged I/K and the squared residual is plotted against lagged I/K; the upward slope is evidence of heteroscedasticity. Additionally, investment rate tends to increase (fall) as the expansion (recession) gets longer. Bachmann, Caballero, and Engel (2010) refer to this as time dependence and it implies that longer expansions (recessions) will be associated with larger increases (decreases) in investment. In the lower panel of Figure 1 we plot the average change in I/K against the length of NBER defined expansions and recessions between 1947 and 2008; coefficients from the associated regressions are positive and significant for expansions and negative and marginally significant for recessions ${ }^{1}$.

These heteroscedasticity and time dependence are especially important during times of high stress (ie long recessions or expansions) but cannot be matched by standard frictionless models as will be discussed in our results. To improve the model performance along this dimension, Bachmann, Caballero, and Engel (2010) provide a counter-example to the Thomas (2002) result of irrelevance of micro-frictions for aggregate dynamics. They argue that the finding of irrelevance is due to calibration: the calibration in Thomas (2002) implies sectoral investment volatility that is too high ${ }^{2}$. With an alternative calibration Bachmann, Caballero, and Engel (2010) show that adding non-convex frictions can help their model match the heteroscedasticity in investment rate. Our analysis contributes to this literature by investigating the asset pricing implications and investment quantities of a general equilibrium model with non-trivial micro-heterogeneity. Different from the existing analysis, we gauge the importance of TFP growth rate shocks instead of the more standard TFP level shocks. We show that the growth rate shocks have important implications for both aggregate investment and asset prices.

\footnotetext{
${ }^{1}$ We have also computed this for U.K. data and the results are similar.

${ }^{2}$ See other related work, e.g., Gourio and Kashyap (2007), House (2008), Bloom, Floetotto, and Jaimovich (2009), etc.
} 
Figure 1: Investment Rate and the Business Cycle

The top panel plots investment rate over time, with NBER contractions dashed. The bottom panel plots $\overline{\Delta I / K}$ against the length of the associated expansion (contraction) where $\overline{\Delta I / K}$ is the difference between the average $I / K$ during the expansion (contraction) and $I / K$ at the start.
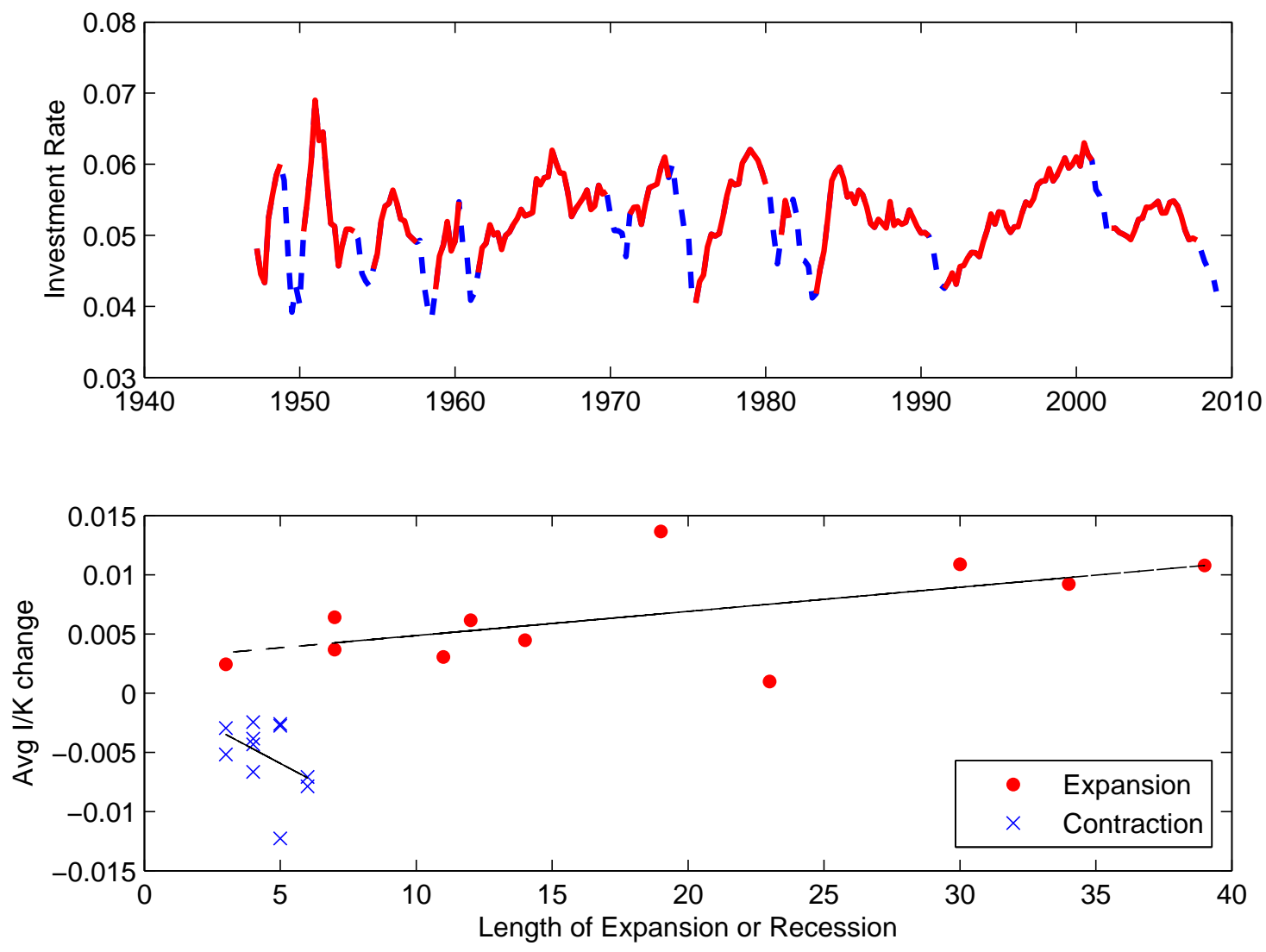
Figure 2: Conditional Heteroscedasticity

This figure presents the heteroscedasticity range, it is analogous to Figure 1 in Bachmann, Caballero, and Engel (2010). First I/K is regressed on its own lag. Next, the squared residuals from this regression are regressed on lagged I/K. Finally, the fitted values from the second regression are plotted against lagged I/K. The appendix describes this procedure in more detail.

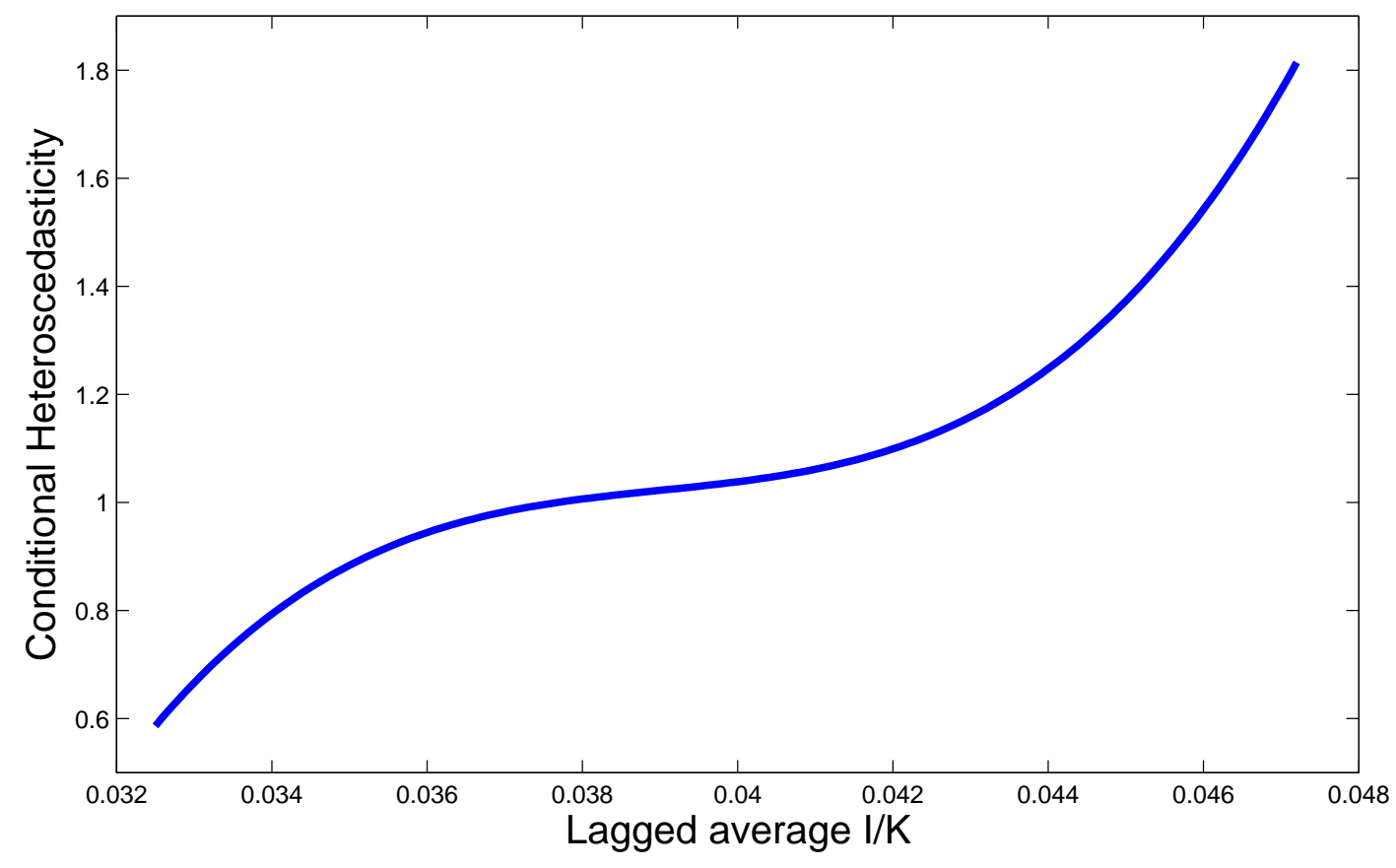




\subsection{Asset Pricing}

Our work also relates to a growing literature on the relationship between asset prices and low frequency shocks. For instance, Tallarini (2000) shows that modeling the growth rate instead of the level of shocks as trend stationary has important implications for welfare and asset pricing. Bansal and Yaron (2004) demonstrate that a small long-run predictable component in the consumption growth process can explain key asset markets phenomena. Alvarez and Jermann (2005) derive a lower bound for the volatility of the permanent component of asset pricing kernels and show that permanent innovations to consumption are key determinants of financial securities. We confirm in our model that the permanent shocks are important for asset prices but differ from Bansal and Yaron (2004) and Alvarez and Jermann (2005): i) instead of assuming shocks to an exogenous consumption growth rate process, consumption is endogenously determined in general equilibrium and the permanent shock in our model is to TFP; ii) the general equilibrium setup allows us to investigate the implications of permanent shocks to aggregate quantities as well as prices.

Finally, our work is related to several papers which study the effect of investment frictions on asset prices in production economies. Jermann (1998) and Boldrin, Christiano, and Fisher (2001) combine habit persistence preferences with investment frictions and show that this helps match both asset pricing and quantity moments. Our economy is closest to recent models by Croce (2010) and Kaltenbrunner and Lochstoer (2010) who show that a combination of low frequency shocks, recursive preferences, and adjustment costs can improve the asset pricing performance in a real business cycle model. However, the above papers consider a representative firm and a representative household; we allow for heterogeneity and study the effects of firm level frictions.

\section{Model}

In this section we describe our model. We begin with the household's problem. We then outline the firm's problem, the economy's key frictions are described here. Finally we define equilibrium. 


\subsection{Households}

In the model financial markets are complete, therefore we consider one representative household who receives labor income, chooses between consumption and saving, and maximizes utility as in Epstein and Zin (1989).

$$
\begin{gathered}
U_{t}=\max \left((1-\beta) C_{t}^{1-1 / \psi}+\beta E_{t}\left[U_{t+1}^{1-\theta}\right]^{\frac{1-1 / \psi}{1-\theta}}\right)^{\frac{1}{1-1 / \psi}} \\
W_{t+1}=\left(W_{t}+N_{t} * w_{t}-C_{t}\right) R_{t+1}
\end{gathered}
$$

where $R_{t+1}$ is the return to a portfolio over all possible financial securities. For simplicity, we assume labor supply is inelastic: $N_{t}=1$. Risk aversion is given by $\theta$ and the intertemporal elasticity of substitution by $\psi$.

\section{$3.2 \quad$ Firms}

The interesting frictions in the model are on the firm's side. Firms choose investment and labor to maximize the present value of future dividend payments where the dividend payments are equal to the firm's output net of investment, wages and various other costs. Output is produced from labor and capital. Firms hold beliefs about the discount factor $M_{t+1}$, which is determined in equilibrium. Firms are indexed by i, which is suppressed where the notation is clear.

$$
\begin{gathered}
V_{t}=\max _{I_{t}} E_{t}\left[\sum_{j=0, \infty} M_{t+j} D_{t+j}\right] \\
D_{t}=\Pi\left(K_{t}\right)-I_{t}-\Phi\left(I_{t}, K_{t}\right) \\
K_{t+1}=(1-\delta) K_{t}+I_{t}
\end{gathered}
$$

$\Pi\left(K_{t}\right)=\max _{N_{t}} Z_{t} K_{t}^{\alpha_{K}} N_{t}^{1-\alpha_{N}}-w_{t} N_{t}-\Psi_{t}$ is profit, given by output less labor and operating $\operatorname{costs}^{3}$. It can be rewritten as $\Pi\left(K_{t}, N_{t}\right)=Z_{t}^{\frac{1}{\alpha_{N}}} X_{t} K_{t}^{\alpha}-\Psi_{t}$ where $\alpha=\alpha_{K} / \alpha_{N}, X_{t}$ is an aggregate

\footnotetext{
${ }^{3}$ As there are no taxes or interest expenses we do not differentiate between operating profit and net income and simply call it profit.
} 
variable that depends only on the aggregate wage ${ }^{4} . Z_{t}$ is the firm's productivity, it includes both aggregate and individual components. The exact form of $Z_{t}$ is discussed in the calibration section further below. $\Psi_{t}$ is operating leverage which also depends only on the aggregate wage; its exact functional form will be described in the calibration section below but in our baseline model it is just proportional to aggregate wages: $\Psi_{t}=f * w_{t}$. When $\alpha_{K}=\alpha_{N}$, output is homogenous of degree one in capital and labor, we will consider decreasing returns to scale: $\alpha_{K}<\alpha_{N}$.

Total capital adjustment costs are given by $\Phi\left(I_{t}, K_{t}\right)$. We consider two types of costs; $\Phi\left(I_{t}, K_{t}\right)$ is the sum of the two. First, fixed costs given by 0 if $\frac{I_{t}}{K_{t}} \in(a, b)$, and $w_{t} \phi * u_{t}$ otherwise where $u_{t}$ is a firm specific, uniform random variable known to firms as of $t^{5}$. Second, asymmetric convex costs given by $v_{t}\left(\frac{I_{t}}{K_{t}}\right)^{2} K_{t}$ where $v_{t}=v^{+}$if $\frac{I_{t}}{K_{t}}>0$ and $v_{t}=v^{-}$otherwise. Asymmetric costs have been shown to quantitatively help with the value premium by Zhang (2005). To sum up:

$$
\Phi_{t}= \begin{cases}v_{t}\left(\frac{I_{t}}{K_{t}}\right)^{2} K_{t} & \text { if } \frac{I_{t}}{K_{t}} \in(\mathrm{a}, \mathrm{b}) \\ v_{t}\left(\frac{I_{t}}{K_{t}}\right)^{2} K_{t}+w_{t} \phi * u_{t} & \text { if } \frac{I_{t}}{K_{t}} \notin(\mathrm{a}, \mathrm{b})\end{cases}
$$

We define the firm's return on capital as $R_{t+1}^{K}=\frac{V_{t+1}}{V_{t}-D_{t}}$. However, real world firms are financed by both debt and equity, with equity being the riskier, residual claim. To compare the model's equity return to empirical equity returns we lever the return on capital using the 2 nd proposition of Modigliani and Miller (1958): $R_{t+1}^{E}-R_{t}^{f}=(1+\lambda)\left(R_{t+1}^{K}-R_{t}^{f}\right)$ where $\lambda$ is the firm's debt to equity ratio $^{6}$.

At this stage it may be useful to compare our model with two closely related models: Khan and Thomas (2008) (KT) and Bachmann, Caballero, and Engel (2010) (BCE). The two key

\footnotetext{
${ }^{4}$ We can define profit in this form because labor is optimized period by period and optimal labor costs are included in $X_{t}$. The derivation of $X_{t}$ is in the appendix.

${ }^{5}$ We follow most of the fixed cost literature (for example Thomas (2002) and Bachmann, Caballero, and Engel (2010)) in choosing the fixed cost to be $w_{t} \phi * u_{t}$ rather than just $\phi$. The presence of $u_{t}$ implies that some firms are low cost firms while others are high cost firms. If fixed costs are more concentrated, investment cycles will end up being coordinated among firms with the same cost and capital. This will lead to predictable, oscillatory dynamics (aka "echo effects" or replacement cycles) in investment. It is unclear whether this type of oscillatory behavior is desirable, for example Gourio and Kashyap (2007) argue that it is, however we do not want it to have first order effects in our model and therefore choose $u_{t}$ to be uniform.

${ }^{6}$ In doing so we assume firms keep leverage constant. We estimate the debt to equity ratio to be 0.59 . Boldrin, Christiano, and Fisher (1999) include leverage in a production economy in the same way and provide additional discussion.
} 
differences are the preferences and the aggregate shocks. In both KT and BCE households have logarithmic utility over consumption; in this paper preferences are recursive as in Epstein and Zin (1989). In both KT and BCE aggregate TFP is trend stationary; in this paper the growth rate of TFP is stationary, making TFP itself non-stationary as in Bansal and Yaron (2004).

There are several other differences, however we believe they are minor and do not contribute to our main result. Labor is inelastic in our model but households have preferences over hours in KT and BCE. KT have one idiosyncratic shock, calibrated at the plant level; BCE have two idiosyncratic shocks, calibrated at the plant and sector level; we have one idiosyncratic shock calibrated at the firm level. This model allows for operating leverage while BCE and KT do not; we will discuss the effect of operating leverage below. We allow for both fixed and convex adjustment costs while BCE and KT allow only fixed. Finally, the form of our fixed cost is identical to $\mathrm{KT}$ in that firms pay no cost when investment rate falls inside (a,b), on the other hand in BCE firms pay no cost if investment rate is equal to $(1-\delta)(1-\chi)+\chi *(1+g)$ where $\mathrm{g}$ is the growth rate of TFP.

\subsection{Equilibrium}

We assume that there exists some underlying set of state variables $S_{t}$ which is sufficient for this problem. Each firm's individual state variables are given by the vector $S_{t}^{i}$. Because the household is a representative agent, we are able to avoid solving the household's maximization problem and simply use the first order conditions to find $M_{t+1}$ as an analytic function of consumption or expectations of future consumption. For instance, with CRRA utility, $M_{t+1}=\beta\left(\frac{C_{t+1}}{C_{t}}\right)^{-\theta}$ while for Epstein-Zin utility $M_{t+1}=\beta\left(\frac{C_{t+1}}{C_{t}}\right)^{-\frac{1}{\psi}}\left(\frac{U_{t+1}}{E_{t}\left[U_{t+1}^{1-\theta}\right]^{\frac{1}{1-\theta}}}\right)^{\frac{1}{\psi}-\theta} \cdot 7$

Equilibrium consists of:

- Beliefs about the transition function of the state variable and the shocks: $S_{t+1}=f\left(S_{t}, Z_{t+1}\right)$

\footnotetext{
${ }^{7}$ Given a process for $C_{t}$ we can recursively solve for all the necessary expectations to calculate $M_{t+1}$. The appendix provides more details.
} 
- Beliefs about the realized stochastic discount factor as a function of the state variable and realized shocks: $M\left(S_{t}, Z_{t+1}\right)$

- Beliefs about aggregate wages as a function of the state variable: $w\left(S_{t}\right)$

- Policy functions (which depend on $S_{t}$ and $S_{t}^{i}$ ) by the firms for labor demand $N_{t}^{i}$ and investment $I_{t}^{i}$

It must also be the case that given the above policy functions all markets clear and the beliefs turn out to be rational:

- The firm's policy functions maximize the firm's problem given beliefs about the wages, the discount factor, and the state variable.

- The labor market clears: $\sum N_{t}^{i}=1$

- The goods market clears: $C_{t}=\sum\left(\Pi_{t}^{i}+\Psi_{t}^{i}+w_{t} N_{t}^{i}-I_{t}^{i}\right)=\sum D_{t}^{i}+w_{t} N_{t}^{i}+\Phi_{t}^{i}+\Psi_{t}^{i}$. Note that here we are assuming that all costs are paid by firms to individuals and are therefore consumed, the results look very similar if all costs are instead wasted.

- The beliefs about $M_{t+1}$ are consistent with goods market clearing through the household's Euler Equation ${ }^{8}$.

- Beliefs about the transition of the state variables are correct. For instance if aggregate capital is part of the aggregate state vector, then it must be that $K_{t+1}=(1-\delta) K_{t}+\sum I_{t}^{i}$.

\section{Results}

\subsection{Calibration}

We solve the model at an annual frequency using a variation of the Krusell and Smith (1998) algorithm, we discuss the solution method in the appendix. The model requires us to choose the

\footnotetext{
${ }^{8}$ For example, with CRRA $M_{t+1}=\beta\left(\frac{\sum D_{t+1, i}+w_{t} N_{t+1, i}+\Phi_{t+1, i}+\Psi_{t+1, i}}{\sum D_{t, i}+w_{t} N_{t, i}+\Phi_{t, i}+\Psi_{t, i}}\right)^{-\theta}$
} 
Table 1: Calibration

Below is the calibration for each of the models we consider. The calibrations in the upper panel (profit growth not calibrated to data) and lower panel (profit growth calibrated to data) are identical except for operating leverage parameters $f$ and $\kappa$.

\begin{tabular}{ccccccccccccccc}
\hline \hline & \multicolumn{11}{c}{ Profit growth not calibrated to data } \\
\hline & $\beta$ & $\theta$ & $\psi$ & $\mathrm{Z}$ & $1-\alpha_{N}$ & $\frac{\alpha_{K}}{\alpha_{N}}$ & $\delta$ & $f$ & $\kappa$ & $v^{+}$ & $v^{-}$ & $(\mathrm{a}, \mathrm{b})$ & $\phi$ \\
\hline 1 & 0.987 & 8 & 2 & $\mathrm{~L}$ & 0.64 & 0.69 & 0.1 & 0.155 & 1 & 0 & 0 & - & 0 \\
2 & 0.987 & 8 & 2 & $\mathrm{~L}$ & 0.64 & 0.69 & 0.1 & 0.155 & 1 & 0.05 & 0.15 & - & 0 \\
3 & 0.987 & 8 & 2 & $\mathrm{~L}$ & 0.64 & 0.69 & 0.1 & 0.155 & 1 & 0 & 0 & $(0,0.1)$ & 0.1 \\
4 & 0.987 & 8 & 2 & $\mathrm{G}$ & 0.64 & 0.69 & 0.1 & 0.146 & 1 & 0 & 0 & - & 0 \\
5 & 0.987 & 8 & 2 & $\mathrm{G}$ & 0.64 & 0.69 & 0.1 & 0.146 & 1 & 0.05 & 0.15 & - & 0 \\
6 & 0.987 & 8 & 2 & $\mathrm{G}$ & 0.64 & 0.69 & 0.1 & 0.146 & 1 & 0 & 0 & $(0,0.1)$ & 0.1 \\
7 & 0.987 & 8 & 2 & $\mathrm{G}$ & 0.64 & 0.69 & 0.1 & 0.146 & 1 & 0.05 & 0.15 & $(0, \infty)$ & 0.05 \\
\hline \hline & \multicolumn{1}{c}{ Profit growth calibrated to data } & & & \\
\hline & $\beta$ & & $\psi$ & $\mathrm{Z}$ & $1-\alpha_{N}$ & $\frac{\alpha_{K}}{\alpha_{N}}$ & $\delta$ & $f$ & $\kappa$ & $v^{+}$ & $v^{-}$ & $(\mathrm{a}, \mathrm{b})$ & $\phi$ \\
\hline 1 & 0.987 & 8 & 2 & $\mathrm{~L}$ & 0.64 & 0.69 & 0.1 & 0.152 & -4.2 & 0 & 0 & - & 0 \\
2 & 0.987 & 8 & 2 & $\mathrm{~L}$ & 0.64 & 0.69 & 0.1 & 0.152 & -4.2 & 0.05 & 0.15 & - & 0 \\
3 & 0.987 & 8 & 2 & $\mathrm{~L}$ & 0.64 & 0.69 & 0.1 & 0.152 & -4.2 & 0 & 0 & $(0,0.1)$ & 0.1 \\
4 & 0.987 & 8 & 2 & $\mathrm{G}$ & 0.64 & 0.69 & 0.1 & 0.055 & 55 & 0 & 0 & - & 0 \\
5 & 0.987 & 8 & 2 & $\mathrm{G}$ & 0.64 & 0.69 & 0.1 & 0.055 & 55 & 0.05 & 0.15 & - & 0 \\
6 & 0.987 & 8 & 2 & $\mathrm{G}$ & 0.64 & 0.69 & 0.1 & 0.055 & 55 & 0 & 0 & $(0,0.1)$ & 0.1 \\
7 & 0.987 & 8 & 2 & $\mathrm{G}$ & 0.64 & 0.69 & 0.1 & 0.055 & 55 & 0.05 & 0.15 & $(0, \infty)$ & 0.05 \\
\hline \hline
\end{tabular}

preference parameters: $\beta$ (time discount factor), $\theta$ (risk aversion), $\psi$ (intertemporal elasticity of substitution); the technology parameters: $\alpha_{N}$ (one minus share of labor), $\alpha_{K}$ (share of capital), $\delta$ (depreciation), $\Psi$ (operating leverage which will depend on two parameters, $f$ and $\kappa$ ); the adjustment cost parameters: $\eta^{+}$(upward convex adjustment cost), $\eta^{-}$(downward convex adjustment cost), $\phi$ (fixed adjustment cost), (a,b) (interval within which no fixed cost is paid). The parameter choices for our preferred model (7), as well as several other models are in Table 1.

Preferences We set $\beta=.987$ to match the level of the risk free rate. We set $\theta=8$ to get a reasonably high Sharpe Ratio while keeping risk aversion within the range recommended by Mehra and Prescott (1985). The intertemporal elasticity of substitution $\psi$ also helps with the Sharpe Ratio, it is set to 2; Bansal and Yaron (2004) show that values above 1 are required for the long run risk channel to match asset pricing moments.

Technology The technology parameters are fairly standard and we use numbers consistent with prior literature. We set $1-\alpha_{N}=.64$ to match the labor share in production and $\alpha_{N}+\alpha_{K}=$ 
.89 to be consistent with estimated degrees of returns to scale ${ }^{9}$. We set $\delta=.1$ to match annual depreciation.

Operating Leverage The functional form for operating leverage is $\Psi_{t}=f *\left(\bar{w}_{t}+\kappa\left(w_{t}-\bar{w}_{t}\right)\right)$ where $w_{t}$ is the wage, $\bar{w}_{t}$ is the wage trend ${ }^{10} . \Psi_{t}$ is a fixed cost from the perspective of the firm, however it depends on the aggregate state of the economy, in particular the wage.

In our baseline case we set $\kappa=1$ implying that $\Psi_{t}=f * w_{t}$. We choose $f$ to match the average market to book ratio in the economy ${ }^{11}$, which we estimate to be 1.34 ; these choices of $f$ are listed in the top panel of Table 1 . We designate models in which $\kappa=1$ and we match the market to book ratio only as A; most of the paper will focus on this case. We have also solved the model with $\kappa=0$ and the results (not reported) are very similar to $\kappa=1$.

However, when $\kappa=1$ equity returns and profits are far too smooth while dividends far too volatile relative to the data; this is a problem in most production based models, for example Croce (2010) and Kaltenbrunner and Lochstoer (2010). In an alternative calibration we choose $\kappa$ to match the volatility of aggregate profit growth and simultaneously choose $f$ to match the average market to book ratio; these choices of $\kappa$ and $f$ are listed in the bottom panel of Table 1 . Although we use $\kappa$ to match profit volatility only, as will be seen below, this greatly improves both equity return and dividend volatilities. We designate models in which we match both the market to book ratio and the profit growth volatility as B. These models have equity volatility that is much closer to the data, we later show that our key results on aggregate investment hold in these models as well.

Adjustment Costs We choose adjustment costs to jointly match volatility of aggregate investment and the distribution of firm level investment rate. Consistent with Cooper and

\footnotetext{
${ }^{9}$ Gomes (2001) uses .95 citing estimates of just under 1 by Burnside (1996). Burnside, Eichenbaum, and Rebelo (1995) estimate it to be between .8 and .9. Khan and Thomas (2008) use .896, justifying it by matching the capital to output ratio. Bachmann, Caballero, and Engel (2010) use .82, justifying it by matching the revenue elasticity of capital.

${ }^{10}$ Recall that the model is non-stationary, $\bar{w}_{t}$ is the non-stationary component of wages while $w_{t}$ is the remaining stationary component.

${ }^{11}$ This is the market to book ratio for the entire firm value (the enterprise value). From Compustat we calculate the market to book ratio for equity to be 1.64 and the book debt to market equity ratio to be 0.59 . Sweeney, Warga, and Winters (1997) find that outside of the Volcker period aggregate market to book values for debt are very close to one. These numbers imply a market to book of 1.34 for enterprise value.
} 
Haltiwager (2006), convex costs are more relevant for aggregate investment and fixed costs more relevant for firm level investment however each cost has some effect on both. Zhang (2005) finds that $\frac{\eta^{-}}{\eta^{+}}=10$ helps to quantitatively match the value premium. We also find that this asymmetry is helpful for matching the distribution of firm level investment rate, however, we find that the level of convex costs in Zhang (2005) leads to aggregate investment that is far too smooth, therefore our level of costs is much smaller with $\eta^{+}=.05$ and $\eta^{-}=.15$. The interval of no fixed cost is $(0, \infty)$ in our preferred model, implying no cost for positive investment; in some specifications the interval is $(0, .1)$ implying no cost only for small investments. The size of the fixed cost affects the autocorrelation of firm level investment, as well as the frequency of spikes and inactions.

Productivity Shocks Recall that a firm's productivity is given by $Z_{t}^{i}$ which is a combination of firm specific and aggregate shocks.

$$
Z_{t}^{i}=A_{t}^{i} Z_{t}^{L}\left(Z_{t}^{G}\right)^{1-\alpha_{N}}
$$

where $A_{t}^{i}$ is firm specific productivity, $Z_{t}^{L}$ is the part of aggregate productivity whose level is trend-stationary, and $Z_{t}^{G}$ is the part of aggregate productivity whose growth rate is stationary ${ }^{12}$. We choose $A_{t}^{i}$ to approximately match the second moment of firm level investment; it is a twostate Markov variable with annual volatility of $30 \%$ and autocorrelation of .6. ${ }^{13}$

While the setup allows for simultaneous shocks to growth and level of productivity, so far we have only solved the model for either only growth or only level productivity shocks. The process for level shocks is

$$
\log \left(Z_{t+1}^{L}\right)=\left(1-\rho^{L}\right) * g * t+\rho^{L} \log \left(Z_{t}^{L}\right)+\sigma^{L} \epsilon_{t+1}^{L}
$$

\footnotetext{
${ }^{12}$ Note that $Z_{t}^{G}$ is a labor augmenting productivity shock. Recall that productivity is $Z_{t} K_{t}^{\alpha_{K}} N_{t}^{1-\alpha_{N}}=$ $Z_{t}^{i} Z_{t}^{L} K_{t}^{\alpha_{K}}\left(N_{t} Z_{t}^{G}\right)^{1-\alpha_{N}}$.

${ }^{13}$ This is roughly consistent with other models. For example $15 \%$ and .62 in Gomes (2001) and $35 \%$ and .69 in Zhang (2005).
} 
The process for growth shocks is

$$
\log \left(\frac{Z_{t+1}^{G}}{Z_{t}^{G}}\right)=g+\rho^{G} \log \left(\frac{Z_{t}^{G}}{Z_{t-1}^{G}}\right)+\sigma^{G} \epsilon_{t+1}^{G}
$$

where $\mathrm{g}=2 \%$ is the mean growth rate of the economy. Note that $\epsilon^{L}$ are transitory shocks to the level of productivity while $\epsilon^{G}$ are transitory shocks to the growth rate of productivity which permanently affect the level of productivity. We set $\rho$ and $\sigma$ to roughly match the autocorrelation and volatility of output.

\subsection{Preferred Model}

We will first present results from our preferred calibration and then show several alternative calibrations to understand what is driving the results.

\subsubsection{Conventional RBC Moments}

Panel A of Table 2 presents the standard business cycle moments for the preferred models and the data. Overall, the model matches these aggregate moments quite well. In the data, depending on the time period output volatility ranges from 1.58\% (1954-2008) to 3.94\% (1930-2008) with higher volatility for the period including the Great Depression. We choose productivity parameters so that the model's output volatility is closer to the lower end of this range. The model also does well with the volatilities and autocorrelations of consumption, investment, and investment growth. The volatilities of investment rate and consumption growth are somewhat high, yet still within the range of the two time periods. The autocorrelation of consumption growth is too high, while its correlation with output growth is too low.

\subsubsection{Aggregate Asset Pricing Moments}

Asset pricing moments are given in Panel B of Table 2. The risk free rate is relatively low and even smoother than the data; this is often a difficult feature to reproduce and occurs here 
because of the high elasticity of intertemporal substitution. On the other hand, the Sharpe Ratio is slightly higher than in the data despite having a risk aversion coefficient of only 8 . This happens due to the long run risk channel of Bansal and Yaron (2004): households with a high elasticity of intertemporal substitution are afraid of changes to expected long run consumption growth. These changes occur due to shocks to expected long run productivity growth, as in Croce (2010) and Kaltenbrunner and Lochstoer (2010).

In model A, the expected excess return on equity is low, however this is not due to low price of risk but rather low quantity of risk. $E\left[R_{e}-R_{f}\right]=S R * \sigma\left(R_{e}-R_{f}\right)$ thus both the price of risk (SR) and the quantity of risk must be high ${ }^{14}$. Model $\mathrm{A}$ is able to match the price of risk, but fails on the quantity of risk. Matching the volatility of equity is a failure of most production models. We find that an alternative formulation of operating leverage helps increase equity volatility while changing little else; these results (Model B) are discussed in a later section.

\subsubsection{Firm Level Investment Dynamics}

Panel C of Table 2 has firm level investment moments, as well as information on heteroscedasticity and time dependence of aggregate investment rate. The model is close to the data for both volatility and autocorrelation of firm level investment. The mean is somewhat below the data because the distribution in the data is more skewed. Similarly, the model does a good job at matching the distribution of investment, which has a large number of spikes (I/K>20\%) and a small number of firms disinvesting. Investment by firms with spikes is important for aggregate investment in both the model and the data, however quantitatively this importance is not quite as high in the model as in the data: investment by firms with spikes accounts for $39 \%$ of all investment compared to $50 \%$ in the data

\footnotetext{
${ }^{14}$ In a similar model Croce (2010) chooses a risk aversion of 30 to get an expected return of 3.0. However he achieves this by overshooting on the Sharpe Ratio (1.9) without having a high enough equity volatility (1.6\%). On the other hand, Kaltenbrunner and Lochstoer (2010) keep risk aversion low, however choose a very high amount of financial leverage. While we believe the channel in Croce (2010) and Kaltenbrunner and Lochstoer (2010) is the right one for the price of risk, we believe future work should resolve both the price of risk and volatility puzzles rather than overshooting on one.
} 


\subsection{Aggregate Investment Dynamics}

In this section we describe the main findings on aggregate investment dynamics and investigate the mechanism behind our model's ability to match conditional heteroscedasticity and timedependence of aggregate investment rates.

Bachmann, Caballero, and Engel (2010) emphasize the importance of heteroscedasticity and time dependence of aggregate investment rate. Below we discuss how to summarize these two observations with summary statistics from the data and the model. Following Bachmann, Caballero, and Engel (2010) we regress aggregate investment rate on its lag and then regress the squared residuals from this regression on lagged investment rate. We then define $\sigma_{x}$ to be the fitted value of the $\mathrm{x}$ percentile of this regression. In the data, $\log \left(\frac{\sigma_{95}}{\sigma_{5}}\right)=0.30$, indicating that investment rate is more volatile when it is high.

To summarize time dependence we use NBER quarterly recession dates and calculate the change in investment rate for each recession and expansion. In particular we calculate the quantity $\overline{\Delta I / K}_{j}=\frac{1}{T_{j}} \sum_{t=0_{j}, T_{j}} \frac{I_{t}}{K_{t}}-\frac{I_{0}}{K_{0}}$ where the expansion or recession $\mathrm{j}$ starts at $0_{j}$ and ends at $T_{j}{ }^{15}$. This measure is plotted against the length of each recession and expansion in the lower panel of Figure 1. We regress $\overline{\Delta I / K}$ on the length of each recession and separately expansion and report the slope coefficients $\gamma^{E}$ and $\gamma^{R}$. We calculate $\log \left(\frac{\sigma_{95}}{\sigma_{5}}\right), \gamma^{E}$, and $\gamma^{R}$ for simulated data from the model in the same way.

The preferred model is able to qualitatively capture these features of the data as reported in Panel C of Table 2. Investment rate is heteroscedastic $\log \left(\frac{\sigma_{95}}{\sigma_{5}}\right)=0.18$, although somewhat less so than 0.30 in the data. As in the data, investment rate rises through an expansion, and falls through a recession: $\gamma^{E}=0.19$, and $\gamma^{R}=-0.35$ compared to 0.08 and -0.49 in the data.

\footnotetext{
${ }^{15}$ We choose this as opposed to $\frac{I_{T}}{K_{T}}-\frac{I_{0}}{K_{0}}$ because NBER dates do not exactly match true changes in underlying shocks and the later measure is more sensitive to such errors, nevertheless, the two give qualitatively similar results.
} 


\subsubsection{Inspecting the Mechanism}

To inspect what works and what does not in allowing the preferred model to match the data, we will study six alternative parameterizations, these are described in Table 1. Panel A presents results for $\kappa=1$ where we choose $f$ to match average market to book only; in Panel B (to be discussed below) we choose $\kappa$ and $f$ to match average market to book and aggregate profit growth volatility. Models 1-3 have only shocks which are trend stationary in the level of productivity while models 5-6 have only shocks which are stationary in the growth rate of productivity. Models 1 and 4 are frictionless, models 2 and 5 have only convex adjustment costs, models 3 and 6 have only non-convex adjustment costs. Recall that model 7 (our preferred model) has a combination of convex and non-convex adjustment costs which we have found to work well. This is a calibration, rather than estimation, exercise and there are likely other parameter combinations that work as well, however we have experimented with a large range of parameters (not reported) and believe the best combination is not far from our preferred calibration ${ }^{16}$.

Selected quantities from the data, the six alternative parameterizations, as well as the preferred model are in Table 3. Results are separated into asset pricing moments, firm level investment moments, and aggregate investment moments.

Starting with the asset pricing moments, it is clear that growth rate stationary, rather than level stationary shocks to productivity are necessary to match high Sharpe Ratios of the data without resorting to very high risk aversion. This happens through the long run risk channel of Bansal and Yaron (2004): households care about expectations of future consumption growth and not just this period's consumption growth. While we only report results in which $\psi=2$, such a high level of the intertemporal elasticity of substitution is a necessary component for this channel in addition to shocks being growth rate stationary (this has also been documented by Croce (2010) and Kaltenbrunner and Lochstoer (2010)). We use these findings as a restriction on technology imposed by asset pricing ${ }^{17}$.

\footnotetext{
${ }^{16}$ Due to the length of time required to solve the model, and the large number of parameters, we have not so far estimated the model. We are considering estimating the model by Simulated Method of Moments as a future direction.

${ }^{17}$ An alternative channel to deliver a high price of risk in a general equilibrium, production economy is habit
} 
Moving on to the firm level investment, a frictionless model (1 and 4) has investment rate that is far too volatile; too many firms have negative investment and those with spikes often have investment rates in excess 100\%; in short investment rate is far wilder than in the data. A convex adjustment cost ( 2 and 5 ) fixes most of these problems by preventing firms from taking very large positive or negative investments. Autocorrelation also increases because for firms with high investment demand it is cheaper to invest over consecutive years rather than all at once. A fixed cost alone (3 and 6) does not do as well as a convex cost along most dimensions. For example, it reduces volatility and increases autocorrelation relative to the frictionless case, but not by enough.

All calibrations with shocks to the growth rate of productivity have a similar I/K pattern to the data: I/K grows as an expansion gets longer $\left(\gamma^{E}>0\right)$ and $\mathrm{I} / \mathrm{K}$ falls as a recession gets longer $\left(\gamma^{R}<0\right)$. Models with shocks to the level of productivity have exactly the opposite pattern. This can be further seen in the lower panel of Figure 3. Here we plot impulse responses of I/K to a one standard deviation positive shock in the random variable governing productivity for a long and a short expansion. In particular, let $x=\log \left(Z^{L}\right)-g * t$ for models 1-3 and $x=\log \left(\Delta Z^{G}\right)-g$ for models 4-6; let $\sigma=\sigma^{L}$ for models $1-3$ and $\sigma=\sigma^{G}$ for models 4-6. Note that $\mathrm{x}=0$ is the normal or average state of productivity. We compare a short expansion, in which x rises from 0 to $\sigma$ for one year and then falls to 0 (solid line), to a long expansion in which $\mathrm{x}$ rises from 0 to $\sigma$ and remains at this value for four consecutive years before falling back to 0 (dashed line) ${ }^{18}$.

In models 1-3, as the expansion gets longer, $\mathrm{I} / \mathrm{K}$ decreases. This is because each level of productivity is associated with an optimal level of capital. A temporary rise in productivity causes firms to increase their target capital level and increase investment immediately. As the expansion gets longer, the target capital level stays at the same level and $\mathrm{I} / \mathrm{K}$ falls because the firms are closer to optimal capital due to past high investment. Adding capital adjustment costs (models 2 and 3) mitigates this feature of the standard model by making it too costly to

preferences, as in Campbell and Cochrane (1999), Jermann (1998), Boldrin, Christiano, and Fisher (2001) among others. Both habit and long run risk have certain desirable as well as undesirable features, which have been debated at length in the literature.

${ }^{18}$ Because shocks follow an $\operatorname{AR}(1)$, this amounts to either one $\epsilon>0$ or four consecutive $\epsilon>0$. 
Figure 3: Impulse Response of Investment Rate

These are impulse responses of investment rate to 1 positive shock or 5 consecutive positive shocks (dashed). In models $1-3$ shocks are to TFP level, in models 4-6 shocks are to TFP growth.
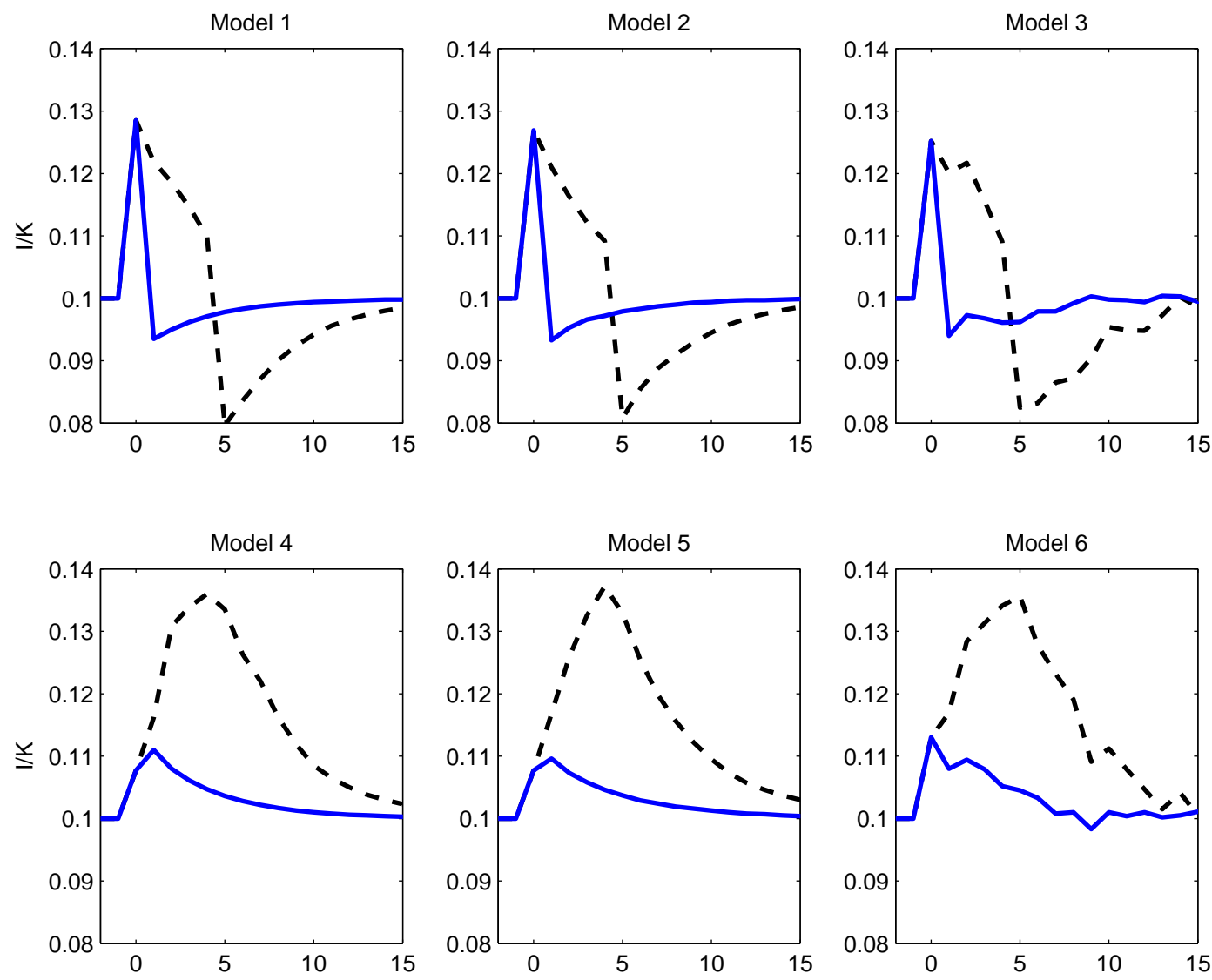
raise investment too much immediately. The result is a flatter decline in investment rate for the parameters we consider, however never a reversal of the decline. Choosing larger adjustment costs may reverse the relationship between investment rate and the length of a recession, but this would make both aggregate and firm level investment far too smooth.

In models 4-6, as the expansion gets longer, $\mathrm{I} / \mathrm{K}$ increases. The reason this happens is straight forward: if the growth rate of productivity is high for a longer number of periods, the level of productivity, and therefore the optimal level of capital continues to grow. Therefore an unexpected lengthening of an expansion leads firms to ramp up investment rather than slow it down, this happens even in a model without frictions.

In a standard model (with shocks to the level of productivity) investment rate is homoscedastic, for example in model 1, $\log \left(\frac{\sigma_{95}}{\sigma_{5}}\right)=-0.01$. Bachmann, Caballero, and Engel (2010) find that an increase in fixed costs increases $\log \left(\frac{\sigma_{95}}{\sigma_{5}}\right)$. We confirm this finding by comparing model 3 to model 1: $\log \left(\frac{\sigma_{95}}{\sigma_{5}}\right)$ rises to $0.09^{19}$. They cite this as evidence for importance of fixed costs. However, models with shocks to the growth rate of productivity (including the frictionless model) all exhibit $\log \left(\frac{\sigma_{95}}{\sigma_{5}}\right)$ moderately close to the data. Thus asset pricing restrictions suggest that nonconvex frictions are unimportant for the aggregate quantities (at least those aggregate quantities that have been considered). Of course non-convex frictions are still important for jointly matching micro and macro findings as in model 7; this is consistent with partial equilibrium findings of Cooper and Haltiwager (2006).

The above results suggest that it may not matter whether Khan and Thomas (2008) or Bachmann, Caballero, and Engel (2010) are fundamentally correct about the relevance of nonconvex micro frictions for aggregates. Quantitatively, a model calibrated at the firm level to match asset pricing moments is able to deliver the desired investment moments with or without non-convex costs. Since model 5 (convex costs only) performs nearly as well as our preferred model (convex costs and small non-convex costs) even at matching firm level micro data, we

\footnotetext{
${ }^{19}$ Their increase is quantitatively bigger than here because their model is not exactly identical to this one. In particular their firms are forced to replace some amount of depreciated capital, this likely increases the quantitative importance of partial equilibrium effects.
} 
provide a micro foundation for convex cost asset pricing models such as Jermann (1998), Zhang (2005), and Croce (2010).

\subsection{Higher Equity and Profit volatility}

Thus far we have shown that the long run risk channel, which has been used in the finance literature to explain several asset pricing puzzles, is also able to explain hard to match aggregate investment moments. However while this channel is indeed able to match the high price of risk, it is not able to match the quantity of risk (volatility) of aggregate equity returns; this is common to most production models. In this section we tweak our model to improve its performance along this dimension and show that the implications for aggregate investment remain unchanged.

The volatility of aggregate profit growth and the volatility of HP filtered profits for the model and the data is in table 3 . It is evident that profits are much more volatile in the data than in standard models, for example the volatility of aggregate profit growth is near $9 \%$ in the data while around 3\% in all versions of $\kappa=1$ model (Panel A of Table 3). The reason for this is that in standard models, wages are more volatile than in the data: the volatility of HP filtered wages in the data is $0.91 \%$ compared to $2.1 \%$ in our preferred model with $\kappa=1$. Since wages are pro-cyclical, profits, which are essentially output minus wages are too smooth.

There are several forces outside of the model, for example long term contracts, which make real world wages smooth. We do not model these forces explicitly and use a reduced form approach instead: we make operating costs counter-cyclical. Recall that profits are given by

$\Pi_{t}=Y_{t}-\left(w_{t} N_{t}+\Psi_{t}\right)$ where $Y_{t}$ is output and $\Psi_{t}$ is the operating cost, therefore by making operating costs covary negatively with wages we are reducing the smoothing effect of pro-cyclical wages. While this approach is admittedly ad hoc, as will be seen below it brings the model much closer to the data among several important dimensions although we are adding only one additional parameter $\kappa$.

We choose $\kappa$ so that the volatility of aggregate profit growth in each model matches the data (simultaneously we must choose a new $f$ to match the average market to book ratio). Recall 
that operating costs are defined as $\Psi_{t}=f *\left(\bar{w}_{t}+\kappa\left(w_{t}-\bar{w}_{t}\right)\right)$ where $w_{t}$ is the wage and $\bar{w}_{t}$ is the wage trend. In models where the level of productivity is trend stationary (Models 1-3) $w_{t}-\bar{w}_{t}$ is pro-cyclical and therefore a negative $\kappa$ is required to make operating costs counter-cyclical ${ }^{20}$. In models where the growth rate of productivity is trend stationary (Models $4-7) w_{t}-\bar{w}_{t}$ is counter-cyclical and therefore a positive $\kappa$ is required $^{21}$. The chosen $f$ and $\kappa$ are listed in the lower panel of Table 1 .

Although we choose $\kappa$ to match only the volatility of profit growth, this also allows the model to do much better on several other key quantities. This can be seen by comparing $\sigma(\Delta \Pi), \sigma(\Delta D)$, and $\sigma\left(R^{e}-R^{f}\right)$ in Panels $\mathrm{A}$ and $\mathrm{B}$ of Table 3. When $\kappa=1$ dividend growth is counter-cyclical and far too volatile. Aggregate dividends are defined as $D_{t}=Y_{t}-\left(I_{t}+w_{t} N_{t}+\Psi_{t}+\Phi_{t}\right)$ and the combination of investment and wages is sufficiently volatile and pro-cyclical to make dividends counter-cyclical in models with $\kappa=1$. A counter-cyclical $\Phi$ reduces the effect of pro-cyclical wages on dividends, leaving dividends pro-cyclical with roughly the right amount of volatility. The volatility of equity returns rises to $10.16 \%$; while this is still just over half of what it is in the data, it is also a nearly five-fold increase compared to standard models. Finally one could think of total labor costs being the combination of fixed and variable labor $\operatorname{costs} w_{t} N_{t}+\Phi_{t}$, the HP filtered volatility of this quantity is $1.2 \%$ in our preferred model B, relatively close to the HP filtered volatility of aggregate wages in the data.

While using $\kappa$ to match profit volatility greatly improves the financial moments of the model, it leaves the other moments nearly unchanged. This can be seen by comparing the remaining rows of Panel A to Panel B in Table 3. Guided by asset pricing restrictions, preferred model B delivers both a high price of risk and quantity of risk and can explain both the heteroscedasticity

\footnotetext{
${ }^{20}$ In these models only the deterministic trend is non-stationary, therefore any variable detrended by $e^{g t}$ becomes stationary. The detrended wage $\nu_{t}$ is pro-cyclical and satisfies $w_{t}=e^{g t} \nu_{t}$. The mean of the detrended wage $\bar{\nu}$ is a constant and satisfies $\bar{w}_{t}=e^{g t} \bar{\nu}$. Therefore operating costs are given by $\Phi_{t}=e^{g t} * f *\left(\bar{\nu}+\kappa\left(\nu_{t}-\bar{\nu}\right)\right)$ and become more pro-cyclical as $\kappa$ increases.

${ }^{21}$ In the appendix we show that dividing each variable by $\left(Z^{G}\right)^{\zeta}$ where $\varepsilon=\frac{1-\alpha_{N}}{1-\alpha_{K}}$ makes each variable stationary. The detrended wage $\nu_{t}$ satisfies $w_{t}=\left(Z^{G}\right)^{\zeta} \nu_{t}$; even though the wage itself is pro-cyclical, the detrended wage is counter-cyclical. The mean of the detrended wage $\bar{\nu}$ is a constant and satisfies $\bar{w}_{t}=\left(Z^{G}\right)^{\zeta} \bar{\nu}$, note that the wage trend itself $\bar{w}_{t}$ is pro-cyclical. Therefore $\nu_{t}-\bar{\nu}$ is counter-cyclical and a sufficiently positive $\kappa$ can make operating costs counter-cyclical.
} 
and time dependence of investment rate.

\section{Conclusion}

We solve a general equilibrium production economy with firm specific productivity shocks resulting in a non-trivial distribution of firms. Within this model, we use insights from asset pricing to shed light on the irrelevance of non-convex frictions debate in the macro literature; we also use insights from the macro literature to guide our modeling choices for matching asset pricing moments.

We use a combination of preferences and technology shocks as in Bansal and Yaron (2004), Croce (2010), Kaltenbrunner and Lochstoer (2010) which are known to help match aggregate asset pricing moments. We find that these ingredients can generate the heteroscedasticity and time-dependence emphasized by Bachmann, Caballero, and Engel (2010). We view asset prices as additional restriction and find that within such a model, non-convex frictions are unnecessary to match important features of aggregate investment. Previous literature, e.g. Bachmann, Caballero, and Engel (2010) has been able to match heteroscedasticity only, by using non-convex frictions, but not simultaneously with asset prices.

We also find that a model with convex costs alone does nearly as good of a job at matching firm level micro data as our preferred model with both convex and non-convex costs. This provides justification for papers such as Jermann (1998), Zhang (2005) and Croce (2010) which use convex costs alone to explain asset prices.

\section{References}

Alvarez, Fernando, and Urban Jermann, 2005, Using asset prices to measure the persistence of the marginal utility of wealth, Econometrica 73, 1977-2016. 
Bachmann, Ruediger, Ricardo Caballero, and Eduardo Engel, 2010, Lumpy investment in dynamic general equilibrium, Working Paper.

Bansal, Ravi, and Amir Yaron, 2004, Risks for the long run: A potential resolution of asset pricing puzzles, Journal of Finance 59, 1481-1509.

Bloom, Nick, Max Floetotto, and Nir Jaimovich, 2009, Really uncertain business cyclces, Working Paper.

Boldrin, M., L. Christiano, and J. Fisher, 1999, Habit persistence, asset returns, and the business cycle, Federal Reserve Bank of Chicago Working Paper No. 99-14.

— 2001, Habit persistence, asset returns, and the business cycle, American Economic Review 91, 149-166.

Burnside, Craig, 1996, Production function regressions, returns to scale, and externalities, Journal of Monetary Economics 37, 177-201.

— - Martin Eichenbaum, and Sergio Rebelo, 1995, Capital utilization and returns to scale, NBER Macroeconomics Annual 10, 67-110.

Caballero, R., and E. Engel, 1999, Explaining investment dynamics in us manufacturing: A generalized (s,s) approach, Econometrica 67, 741-782.

— , and J. Haltiwanger, 1995, Plant-level adjustment and aggregate investment dynamics, Brookings Papers on Economic Activity 2, 1-54.

— , 1997, Aggregate employment dynamics: Building from microeconomics, American Economic Review 87, 115-137.

Campbell, John Y., and John H. Cochrane, 1999, By force of habit: A consumption-based explanation of aggregate stock market behavior, Journal of Political Economy 107, 205-251. 
Cooper, R. W., and J.C. Haltiwager, 2006, On the nature of capital adjustment costs, Review of Economic Studies 73, 611-633.

Croce, Max, 2010, Long-run productivity risk: A new hope for production-based asset pricing?, Working Paper.

Davis, S., and J. Haltiwanger, 1992, Gross job creation, gross job destruction, and employment reallocation, Quarterly Journal of Economics 107, 819-864.

Doms, M., and T. Dunne, 1998, Capital adjustment patterns in manufacturing plants, Review of Economic Dynamics 1, 409-429.

Epstein, Larry, and Stanley Zin, 1989, Substitution, risk aversion, and the temporal behavior of consumption and asset returns: a theoretical framework, Econometrica 57, 937-969.

Garleanu, Nicolae, Stavros Panageas, and Jianfeng Yu, 2009, Technological growth and asset pricing, Working Paper.

Gomes, Joao, 2001, Financing investment, American Economic Review 91, 1263-1285.

— Leonid Kogan, and Lu Zhang, 2003, Equilibrium corss section of returns, Journal of Political Economy 111, 693-732.

Gourio, F., and A.K. Kashyap, 2007, Investment spikes: New facts and a general equilibrium exploration, Journal of Monetary Economics 54, 1-22.

House, C.L., 2008, Fixed costs and long-lived investments, Working Paper.

Jermann, Urban J., 1998, Asset pricing in production economies, Journal of Monetary Economics $41,257-275$.

Kaltenbrunner, Georg, and Lars Lochstoer, 2010, Long-run risk through consumption smoothing, forthcoming Review of Financial Studies. 
Khan, Aubhik, and Julia Thomas, 2003, Nonconvex factor adjustments in equilibrium business cycle models: Do nonlinearities matter?, Jounral of Monetary Economics 50, 331-360.

— , 2008, Idiosyncratic shocks and the role of nonconvexities in plant and aggregate investment dynamics, Econometrica 76, 395-436.

Krusell, Per, and Anthony A. Smith, Jr., 1998, Income and wealth heterogeneity in the macroeconomy, The Journal of Political Economy 106, 867-896.

Marcet, Albert, and Thomas Sargent, 1989, Convergence of least squares learning mechanisms in self-referential linear stochastic models, Journal of Economic Theory 48, 337-368.

Mehra, Rajnish, and Edward Prescott, 1985, The equity premium: A puzzle, Journal of Monetary Economics 15, 145-161.

Modigliani, F., and M. Miller, 1958, The cost of capital, corporation finance and the theory of investment, American Economic Review 48, 261-297.

Sweeney, Richard, Arthur Warga, and Drew Winters, 1997, The market value of debt, market versus book value of debt, and returns to assets, Financial Management 26, 5-21.

Tallarini, T.D., 2000, Risk sensitive real business cycles, Journal of Monetary Economics 45, $507-532$.

Thomas, J.K., 2002, Is lumpy investment relevant for the business cycle?, Journal of Political Economy 110, 508-534.

Tuzel, Selale, 2010, Corporate real estate holdings and the cross-section of stock returns, Review of Financial Studies 23, 2268-2302.

Veracierto, M., 2002, Plant level irreversible investment and equilibrium business cycles, American Economic Review 92, 181-197.

Zhang, Lu, 2005, The value premium, Journal of Finance 60, 67-103. 


\section{A Data}

Monthly stock returns are from the Center for Research in Security Prices (CRSP) and accounting information is from the CRSP/Compustat Merged Annual Industrial Files. Our sample is from 1975 to 2009 . We exclude from the sample any firm-year observation with missing data or for which total assets or the gross capital stock are either zero or negative. In addition, as standard, we omit firms whose primary SIC classification is between 4900 and 4999 (regulated firms) or between 6000 and 6999 (financial firms). Following Cooper and Haltiwanger (2006), We define the capital stock, $\mathrm{K}$, as gross property, plant and equipment, and investment (PPEGT in Compustat), I, as capital expenditures (CAPX) minus sales of property, plant and equipment (SPPE). Incorporating sales of capital is especially important in our analysis as the role of partial irreversibility is quite difficult to study with the use of capital expenditures data alone. Both capital and investment are deflated by the domestic fixed investment price deflator. Investment rate IK is defined as investment scaled by lagged capital stock, which can be either positive or negative. The gross domestic fixed investment price deflator is from NIPA table 1.1.9. GDP is real gross domestic product from NIPA table 1.1.6; real consumption is nondurable consumption from NIPA table 2.3.5, scaled by implicit price for nondurable expenditures from NIPA table 2.3.4. Investment is investment in private non-residential fixed assets from NIPA table 4.7. Capital is private non-residential fixed assets from NIPA table 4.1. Both investment and capital are scaled by investment price deflator to get real terms. Wage is compensation of employees from NIPA table 6.2 divided by hours worked by full-time and part-time employees from NIPA table 6.9. Annual dividend is aggregated over monthly dividend from Robert Shiller's webpage: http://www.econ.yale.edu/ shiller/data.htm. CRSP value-weighted market returns and risk free rates are from Ken French webpage: http://mba.tuck.dartmouth.edu/pages/faculty/ken.french/data_library.1

Firm profit is net sales (SALE) minus the sum cost of good sold (COGS) and selling, general and administrative expense (XSGA). We aggregate all firms' profit scaled by investment price deflator to get total real profit. 


\section{A.1 Conditional Heteroscedasticity in Aggregate U.S. Investment}

Following Bachmann, Caballero, and Engel (2010), we work with quarterly private fixed nonresidential investment to capital ratio from 1960:I to 2009:IV, denoted by $x_{t}$ and estimate the following time-series model to quantify conditional heteroscedasticity:

$$
\begin{aligned}
x_{t} & =\phi x_{t-1}+\sigma_{t} e_{t} \\
\sigma_{t} & =\alpha_{0}+\alpha_{1} \bar{x}_{t-1}^{k},
\end{aligned}
$$

where $\bar{x}_{t-1}^{k}$ denotes the lagged average investment:

$$
\bar{x}_{t-1}^{k}=\frac{1}{k} \sum_{j=0}^{k-1} x_{t-1-j}
$$

and the $e_{t}$ are i.i.d with zero mean and variance equal to one. We estimate the parameters of the above time-series model by first regressing $x_{t}$ on its lagged value and then regressing the squared residual from the first regression, denoted by $\hat{e}_{t}^{2}$, on $\bar{x}_{t-1}^{k}$. The second regression has the following form

$$
\hat{e}_{t}^{2}=\hat{\alpha}_{0}+\hat{\alpha}_{1} \bar{x}_{t-1}^{k}+\text { error }
$$

Figure 2 plots the fitted trend line from the second regression (normalized by the average fitted value for $\sigma_{t}$ ) using $k=5$.

\section{B Numerical Solution}

\section{B.1 Making the Model Stationary}

Note that the model is not stationary. In order to solve it numerically, we must rewrite it in terms of stationary quantities. Let $\varepsilon=\frac{1-\alpha_{N}}{1-\alpha_{K}}$. We will first show that normalizing all variables by $\left(Z^{G}\right)^{\varepsilon}$ makes them stationary.

First consider the firm's problem without operating leverage, without fixed costs, and with 
$Z^{G}$ shocks only, for simplicity we will refer to $Z^{G}$ as simply $Z$ here. Within each period the firm chooses labor to maximize profits:

$$
\Pi\left(K_{t}\right)=\max _{N_{t}} Z_{t}^{1-\alpha_{N}} K_{t}^{\alpha_{K}} N_{t}^{1-\alpha_{N}}-w_{t} N_{t}
$$

The first order conditions give:

$$
N_{t}=\left(1-\alpha_{N}\right)^{\frac{1}{\alpha_{N}}} Z_{t}^{\frac{1-\alpha_{N}}{\alpha_{N}}} K_{t}^{\frac{\alpha_{K}}{\alpha N}} w_{t}^{-\frac{1}{\alpha N}}
$$

This can be plugged back into the profit equation to solve for firm's profits under optimal labor given aggregate wages:

$$
\Pi\left(K_{t}\right)=\alpha_{N}\left(1-\alpha_{N}\right)^{\frac{1-\alpha_{N}}{\alpha_{N}}} Z_{t}^{\frac{1-\alpha_{N}}{\alpha_{N}}} w_{t}^{-\frac{1-\alpha_{N}}{\alpha_{N}}} K_{t}^{\frac{\alpha_{K}}{\alpha_{N}}}
$$

The firm's full dynamic problem can now be rewritten recursively in terms of aggregate quantities $Z_{t}, w_{t}$, and $M_{t+1}$, the firm's capital $K_{t}$, and a single choice variable $I_{t}$ :

$$
V\left(K_{t}\right)=\max _{I_{t}} \alpha_{N}\left(1-\alpha_{N}\right)^{\frac{1-\alpha_{N}}{\alpha_{N}}} Z_{t}^{\frac{1-\alpha_{N}}{\alpha_{N}}} w_{t}^{-\frac{1-\alpha_{N}}{\alpha_{N}}} K_{t}^{\frac{\alpha_{K}}{\alpha_{N}}}-I_{t}-v_{t}\left(\frac{I_{t}}{K_{t}}\right)^{2} K_{t}+E_{t}\left[M_{t+1} V\left(K_{t+1}\right)\right]
$$

subject to $K_{t+1}=(1-\delta) K_{t}+I_{t}$ and $Z_{t+1}=Z_{t} S_{t+1}$ where $S_{t}$ is a stationary variable.

We will now normalize all appropriate variables by $Z_{t}^{\varepsilon}$, it will later be shown that this normalization makes the variables stationary. Let $k_{t}=K_{t} / Z_{t}^{\varepsilon}, \nu_{t}=w_{t} / Z_{t}^{\varepsilon}$, and $i_{t}=I_{t} / Z_{t}^{\varepsilon}$. Note that $k_{t+1}=\left((1-\delta) k_{t}+i_{t}\right) S_{t+1}^{-\varepsilon}$ and that $V\left(K_{t+1}\right)=V\left(k_{t+1} S_{t+1}^{\varepsilon} Z_{t}^{\varepsilon}\right)$.

$$
\begin{aligned}
V\left(k_{t} Z_{t}^{\varepsilon}\right) & =\max _{i_{t}} \alpha_{N}\left(1-\alpha_{N}\right)^{\frac{1-\alpha_{N}}{\alpha_{N}}} Z_{t}^{\frac{1-\alpha_{N}}{\alpha_{N}}}\left(\nu_{t} Z_{t}^{\varepsilon}\right)^{-\frac{1-\alpha_{N}}{\alpha_{N}}}\left(k_{t} Z_{t}^{\varepsilon}\right)^{\frac{\alpha_{K}}{\alpha_{N}}}-i_{t} Z_{t}^{\varepsilon}-v_{t}\left(\frac{i_{t}}{k_{t}}\right)^{2} k_{t} Z_{t}^{\varepsilon}+ \\
& E_{t}\left[M_{t+1} V\left(k_{t+1} S_{t+1}^{\varepsilon} Z_{t}^{\varepsilon}\right)\right] \\
V\left(k_{t} Z_{t}^{\varepsilon}\right) & =\max _{i_{t}} \alpha_{N}\left(1-\alpha_{N}\right)^{\frac{1-\alpha_{N}}{\alpha_{N}}} Z_{t}^{\varepsilon} \nu_{t}^{-\frac{1-\alpha_{N}}{\alpha_{N}}} k_{t}^{\frac{\alpha_{K}}{\alpha_{N}}}-i_{t} Z_{t}^{\varepsilon}-v_{t}\left(\frac{i_{t}}{k_{t}}\right)^{2} k_{t} Z_{t}^{\varepsilon}+E_{t}\left[M_{t+1} V\left(k_{t+1} S_{t+1}^{\varepsilon} Z_{t}^{\varepsilon}\right)\right]
\end{aligned}
$$


Next, we will show by recursion that $V\left(K_{t}\right)$ is linear in $Z_{t}^{\varepsilon}$. Suppose this is true at $\mathrm{t}+1$ :

$$
V\left(K_{t+1}\right)=V\left(k_{t+1} S_{t+1}^{\varepsilon} Z_{t}^{\varepsilon}\right)=V\left(k_{t+1}\right) S_{t+1}^{\varepsilon} Z_{t}^{\varepsilon}
$$

Then the firm's problem can be rewritten as:

$$
\begin{aligned}
V\left(k_{t} Z_{t}^{\varepsilon}\right) & \left.=\max _{i_{t}} Z_{t}^{\varepsilon}\left(\alpha_{N}\left(1-\alpha_{N}\right)^{\frac{1-\alpha_{N}}{\alpha_{N}}} \nu_{t}^{-\frac{1-\alpha_{N}}{\alpha_{N}}} k_{t}^{\frac{\alpha_{K}}{\alpha_{N}}}-i_{t}-v_{t}\left(\frac{i_{t}}{k_{t}}\right)^{2} k_{t}+E_{t}\left[M_{t+1} V\left(k_{t+1}\right) S_{t+1}^{\varepsilon}\right)\right]\right) \\
& =\max _{i_{t}} Z_{t}^{\varepsilon} V\left(k_{t}\right)
\end{aligned}
$$

Therefore, by induction, we have shown that the firm's value function is linear in $Z_{t}^{\varepsilon}$ and we can rewrite the dynamic problem as:

$$
\left.V\left(k_{t}\right)=\max _{i_{t}} \alpha_{N}\left(1-\alpha_{N}\right)^{\frac{1-\alpha_{N}}{\alpha_{N}}} \nu_{t}^{-\frac{1-\alpha_{N}}{\alpha_{N}}} k_{t}^{\frac{\alpha_{K}}{\alpha_{N}}}-i_{t}-v_{t}\left(\frac{i_{t}}{k_{t}}\right)^{2} k_{t}+E_{t}\left[M_{t+1} V\left(k_{t+1}\right) S_{t+1}^{\varepsilon}\right)\right]
$$

where $k_{t+1}=\left((1-\delta) k_{t}+i_{t}\right) S_{t+1}^{-\varepsilon}$ and $S_{t+1}$ is a stationary random variable. Note that we have yet to justify the normalization by $Z_{t}^{\varepsilon}$ or show that $\nu_{t}$ is stationary, however the rewriting of the problem above is correct regardless of whether it is the proper normalization. We will now argue that $Z_{t}^{\varepsilon}$ is the proper normalization.

Suppose that each firm believes that $\nu_{t}$ is stationary. Than everything is stationary in the problem above and optimal behavior will lead to a stationary $k_{t}$. We can rewrite firm i's labor demand $N_{t}^{i}$ (solved for above) in terms of detrended variables

$$
N_{t}^{i}=\left(1-\alpha_{N}\right)^{\frac{1}{\alpha_{N}}} Z_{t}^{\frac{1-\alpha_{N}}{\alpha_{N}}}\left(k_{t} Z_{t}^{\varepsilon}\right)^{\frac{\alpha_{K}}{\alpha_{N}}}\left(\nu_{t} Z_{t}^{\varepsilon}\right)^{-\frac{1}{\alpha_{N}}}=\left(1-\alpha_{N}\right)^{\frac{1}{\alpha_{N}}} k_{t}^{\frac{\alpha_{K}}{\alpha_{N}}} \nu_{t}^{-\frac{1}{\alpha_{N}}}
$$

Note that $Z_{t}$ drops out of the equation and labor demand depends only on the detrended wage $\nu_{t}$ and the firm's detrended capital $k_{t}$. Thus if the firm believes that $\nu_{t}$ is stationary than its labor demand is also stationary. 
In equilibrium aggregate labor demand must equal to aggregate labor supply:

$$
1=\sum N_{t}^{i}=\sum\left(1-\alpha_{N}\right)^{\frac{1}{\alpha_{N}}} k_{t}^{\frac{\alpha_{K}}{\alpha_{N}}} \nu_{t}^{-\frac{1}{\alpha_{N}}}=\left(1-\alpha_{N}\right)^{\frac{1}{\alpha_{N}}} \nu_{t}^{-\frac{1}{\alpha_{N}}} \sum k_{t}^{\frac{\alpha_{K}}{\alpha_{N}}}
$$

which we can solve for the detrended wage: $\nu_{t}=\left(\frac{1}{\left(1-\alpha_{N}\right)^{\frac{1}{\alpha_{N}}} \sum k_{t}^{\frac{\alpha_{K}}{\alpha_{N}}}}\right)^{-\alpha_{N}} \cdot$ Thus, if firms believe that $\nu_{t}$ is stationary, they will optimally act in such a way that $\nu_{t}$ will indeed be stationary and that $Z_{t}^{\varepsilon}$ will be the correct normalization.

We have so far ignored operating leverage and fixed costs, however the same normalization works as long as we defined these costs such that they are stationary in the detrended model. This is what we do. Operating leverage is defined as $\Psi_{t}=f *\left(\bar{w}_{t}+\kappa\left(w_{t}-\bar{w}_{t}\right)\right)$ which is stationary in the detrended model because detrended wages are stationary and by definition $\bar{w}_{t} / Z_{t}^{\varepsilon}$ is constant. The fixed investment cost is linear in wages so it is also stationary in the detrended model.

\section{B.2 Numerical Algorithm}

We will now describe the numerical algorithm used to solve the stationary problem above. We will first describe the algorithm used to solve a model with CRRA utility and then the extension necessary to solve the recursive utility version. The algorithm is a variation of the algorithm in Krusell and Smith (1998).

The state space is potentially infinite because it contains the full distribution of capital across firms. We follow Krusell and Smith (1998) and summarize it by the average aggregate capital $\bar{k}_{t}$ and the state of aggregate productivity $\left(Z_{t}\right.$ in models 1-3 and $\log \left(Z_{t} / Z_{t-1}\right)$ in models 4-7). Each of these is put on a grid with grid sizes for capital being 45, while productivity is discretized to be a 3-state Markov process (we have also solved some of the versions with a 7-state Markov process and the results are very similar). We also discretize the firm's individual capital with the grid size being 45. In models where the fixed cost of investment is non-zero there is an additional firm level state variable: the cost drawn from a uniform distribution each period. We discretize this on a grid with 7 points. 
For each point in the aggregate state space $\left(\bar{k}_{t}, Z_{t}\right)$ we start out with an initial belief about consumption, wages, and investment $\left(c_{t}, \nu_{t}\right.$, and $\left.i_{t}\right){ }^{22}$ From these we can solve for aggregate capital next period $\bar{k}_{t+1}=\left((1-\delta) \bar{k}_{t}+i_{t}\right) S_{t+1}^{-\varepsilon}$ for each realization of the shock. Combining $\bar{k}_{t+1}$ with beliefs about consumption as a function of capital we can also solve for the stochastic discount factor next period: $M_{t+1}=\beta\left(\frac{c_{t+1}}{c_{t}}\right)^{-\theta} S_{t+1}^{-\varepsilon \theta}$. This is enough information to solve the stationary problem described in the previous section. We solve the problem by value function iteration with the output being policies and market values of each firm for each point in the state space.

The next step is to use the policy functions to simulate the economy. We simulate the economy for 5500 periods (we throw away the initial 500 periods). Additionally we start off the model in each point of the aggregate state space. We do this because unlike Krusell and Smith (1998), the beliefs do not have a parametric form and during the model's typical behavior it does not visit every possible point in the state space. From the simulation we form simulation implied beliefs about $c_{t}, \nu_{t}$, and $i_{t}$ at each point in the aggregate state space by averaging over all periods in which the economy was sufficiently close to that point in the state space. Our updated beliefs are a weighted average of the old beliefs and the simulation implied beliefs ${ }^{23}$. With these updated beliefs we again solve the firm's dynamic program; we continue doing this until convergence.

In order to solve this model with recursive preferences an additional step is required. Knowing $c_{t}$ and $k_{t+1}$ as functions of the aggregate state is not alone enough to know $M_{t+1}$ because in addition to consumption growth, it depends on the household's value function next period: $M_{t+1}=\beta\left(\frac{C_{t+1}}{C_{t}}\right)^{-\frac{1}{\psi}}\left(\frac{U_{t+1}}{E_{t}\left[U_{t+1}^{1-\theta}\right]^{\frac{1}{1-\theta}}}\right)^{\frac{1}{\psi}-\theta}$. However this problem is not difficult to overcome. After

\footnotetext{
${ }^{22}$ The standard Krusell and Smith (1998) algorithm instead assumes a functional form for the transition, such as $\log \left(\bar{k}_{t+1}\right)=A\left(Z_{t}\right)+B\left(Z_{t}\right) \log \left(\bar{k}_{t}\right)$ and forms beliefs only about the coefficients $A\left(Z_{t}\right)$ and $B\left(Z_{t}\right)$ however we find that this approach does not converge in many cases due to incorrect beliefs about off-equilibrium situations and that our approach works better. Without heterogeneity we would not need beliefs about $\nu_{t}$ because it would just be the marginal product of aggregate capital; due to firm heterogeneity it is not quite equal to the marginal product of aggregate capital. Similarly, we would not need beliefs about $c_{t}$ as we could solve for it from $y_{t}=c_{t}+i_{t}$ where $y_{t}$ is aggregate output, however aggregate output is no longer a simple analytic function of aggregate capital.

${ }^{23}$ The weight on the old belief is often required to be very large in order for the algorithm to converge. This is because while rational equilibria exist, they are only weakly stable in the sense described by Marcet and Sargent (1989).
} 
each simulation step we use beliefs about $c_{t}$ and $k_{t+1}$ to recursively solve for the household's value function at each point in the state space. This is again done through value function iteration, however as there are no choice variables this recursion is very quick.

We perform the standard checks proposed by Krusell and Smith (1998) to make sure we have found the equilibrium. Although our beliefs are non-parametric, we can still compute an $R^{2}$ analogous to a regression; all of our $R^{2}$ are above 0.9999 . We have also checked that an additional state variable (either the cross-sectional standard deviation of capital or lagged capital) does not alter the results. 

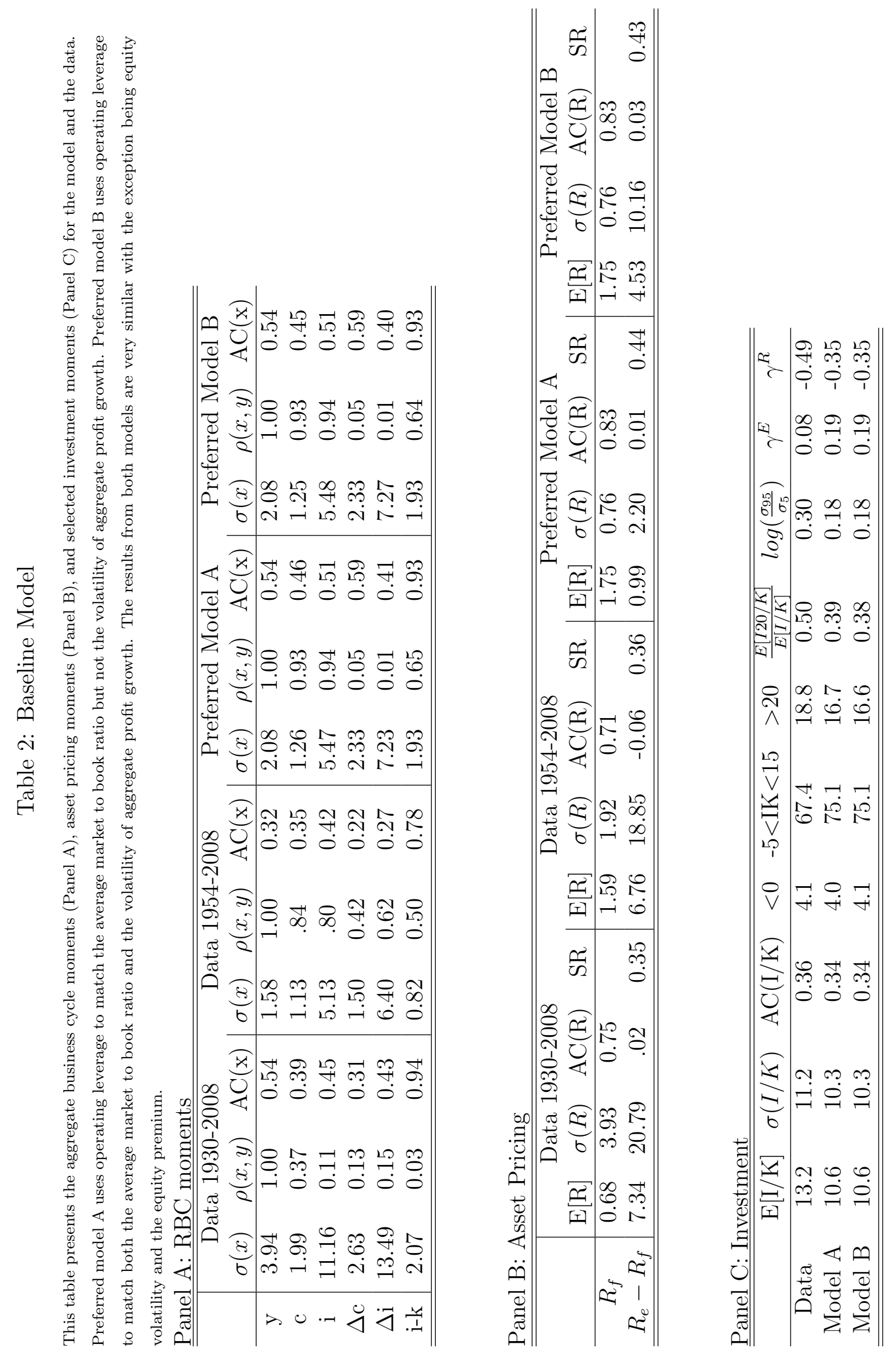
Table 3: Inspecting the Mechanism

The rows are separated into asset pricing moments (1-6), firm level investment (7-12), and aggregate investment (13-15). In the upper panel operating leverage is not calibrated to match the average market to book ratio but not the volatility of aggregate profit growth. In the lower panel operating leverage is calibrated to match both the average market to book ratio and the volatility of aggregate profit growth.

Panel A: Profit growth not calibrated to data

\begin{tabular}{|c|c|c|c|c|c|c|c|c|}
\hline $\begin{array}{c}\text { Shock } \\
\text { Cost }\end{array}$ & Data & $\begin{array}{c}1 \\
\text { L } \\
\text { None }\end{array}$ & $\begin{array}{c}2 \\
\mathrm{~L} \\
\text { Convex }\end{array}$ & $\begin{array}{c}3 \\
\text { L } \\
\text { Fixed } \\
\end{array}$ & $\begin{array}{c}4 \\
\text { G } \\
\text { None } \\
\end{array}$ & $\begin{array}{c}5 \\
\mathrm{G} \\
\text { Convex }\end{array}$ & $\begin{array}{c}6 \\
\text { G } \\
\text { Fixed } \\
\end{array}$ & $\begin{array}{c}7 \\
\text { G } \\
\text { Both } \\
\end{array}$ \\
\hline Sharpe Ratio & 0.36 & 0.01 & 0.01 & 0.01 & 0.43 & 0.44 & 0.43 & 0.44 \\
\hline$\sigma\left(R^{e}-R^{f}\right)$ & 18.85 & 0.56 & 0.72 & 0.57 & 2.12 & 2.19 & 2.08 & 2.20 \\
\hline$\sigma(\Delta \Pi)$ & 8.85 & 2.87 & 2.88 & 2.87 & 3.15 & 3.15 & 3.14 & 3.15 \\
\hline$\sigma(\Pi)$ & 6.74 & 2.01 & 2.01 & 2.01 & 2.08 & 2.09 & 2.08 & 2.09 \\
\hline$\sigma(\Delta D)$ & 8.75 & 47.66 & 43.95 & 46.92 & 155.31 & 142.20 & 152.73 & 142.19 \\
\hline$\sigma(D)$ & 6.94 & 33.31 & 30.66 & 32.56 & 116.95 & 106.20 & 113.71 & 106.02 \\
\hline $\mathrm{I} / \mathrm{K}<0$ & 4.2 & 10.0 & 20.1 & 6.2 & 10.0 & 20.7 & 5.8 & 4.0 \\
\hline$-5<\mathrm{I} / \mathrm{K}<15$ & 67.4 & 80.0 & 67.5 & 85.8 & 80.0 & 67.3 & 85.6 & 75.1 \\
\hline $\mathrm{I} / \mathrm{K}>20$ & 19.8 & 10.0 & 18.1 & 8.2 & 10.0 & 18.5 & 8.5 & 16.7 \\
\hline$\sigma(I / K)$ & 11.2 & 63.4 & 12.0 & 31.4 & 63.5 & 11.7 & 30.8 & 10.3 \\
\hline$A C(I / K)$ & 0.36 & -0.17 & 0.29 & -0.04 & -0.16 & 0.32 & -0.03 & 0.34 \\
\hline$\frac{E[I 20 / K]}{E[I / K]}$ & 0.50 & 1.03 & 0.46 & 0.54 & 1.02 & 0.47 & 0.54 & 0.39 \\
\hline $\log \left(\frac{\sigma_{95}}{\sigma_{5}}\right)$ & 0.30 & -0.01 & 0.02 & 0.09 & 0.18 & 0.18 & 0.20 & 0.18 \\
\hline$\gamma^{E}$ & 0.08 & -0.01 & -0.01 & -0.01 & 0.20 & 0.20 & 0.20 & 0.19 \\
\hline$\gamma^{R}$ & -0.49 & 0.09 & 0.08 & 0.08 & -0.37 & -0.36 & -0.38 & -0.35 \\
\hline \multicolumn{9}{|c|}{ Panel B: Profit growth calibrated to data } \\
\hline & Data & $\overline{1}$ & 2 & 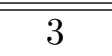 & 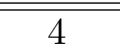 & $\overline{5}$ & $\overline{66}$ & $\overline{7}$ \\
\hline Shock & & $\mathrm{L}$ & $\mathrm{L}$ & $\mathrm{L}$ & G & G & G & G \\
\hline Cost & & None & Convex & Fixed & None & Convex & Fixed & Both \\
\hline Sharpe Ratio & 0.36 & 0.01 & 0.01 & 0.01 & 0.43 & 0.43 & 0.43 & 0.43 \\
\hline$\sigma\left(R^{e}-R^{f}\right)$ & 18.85 & 2.59 & 2.77 & 2.58 & 9.89 & 10.19 & 9.45 & 10.16 \\
\hline$\sigma(\Delta \Pi)$ & 8.85 & 8.55 & 8.62 & 8.47 & 8.40 & 8.38 & 8.24 & 8.30 \\
\hline$\sigma(\Pi)$ & 6.74 & 5.96 & 6.00 & 5.90 & 6.38 & 6.37 & 6.27 & 6.30 \\
\hline$\sigma(\Delta D)$ & 8.75 & 14.75 & 10.55 & 13.71 & 15.83 & 12.80 & 14.45 & 12.59 \\
\hline$\sigma(D)$ & 6.94 & 11.47 & 8.79 & 10.86 & 11.19 & 9.51 & 10.26 & 9.48 \\
\hline $\mathrm{I} / \mathrm{K}<0$ & 4.2 & 10.0 & 20.3 & 6.2 & 10.0 & 20.3 & 5.8 & 4.1 \\
\hline$-5<\mathrm{I} / \mathrm{K}<15$ & 67.4 & 80.0 & 67.5 & 85.8 & 80.0 & 67.1 & 85.6 & 75.1 \\
\hline $\mathrm{I} / \mathrm{K}>20$ & 19.8 & 10.0 & 18.1 & 8.2 & 10.0 & 18.2 & 8.5 & 16.6 \\
\hline$\sigma(I / K)$ & 11.2 & 63.3 & 12.0 & 31.4 & 63.6 & 11.7 & 30.8 & 10.3 \\
\hline$A C(I / K)$ & 0.36 & -0.17 & 0.29 & -0.04 & -0.16 & 0.32 & -0.03 & 0.34 \\
\hline$\frac{E[I 20 / K]}{E[I / K]}$ & 0.50 & 1.03 & 0.46 & 0.54 & 1.03 & 0.47 & 0.54 & 0.38 \\
\hline $\log \left(\frac{\sigma_{95}}{\sigma_{5}}\right)$ & 0.30 & -0.01 & 0.01 & 0.09 & 0.16 & 0.17 & 0.19 & 0.18 \\
\hline$\gamma^{E^{j}}$ & 0.08 & -0.01 & -0.01 & -0.01 & 0.20 & 0.20 & 0.20 & 0.19 \\
\hline$\gamma^{R}$ & -0.49 & 0.09 & 0.08 & 0.09 & -0.36 & -0.36 & -0.36 & -0.35 \\
\hline
\end{tabular}

